\title{
Формы проявления термального воздействия интрузивов базитов на вмещающие породы и возможные причины их различия на примерах северо-восточной части Балтийского щита
}

\section{Травин В.В.}

Институт геологии КарНЦ РАН, Петрозаводск, vetr@list.ru

Аннотация. В статье рассматриваются гранофировые граниты (полностью переплавленные породы), в разной степени расплавленные породы с гранофировыми структурами и гранитоиды с гранобластовыми структурами, подобными структурам роговиков. Обсуждаются возможные причины различий термального воздействия интрузий базитов. Имеющиеся данные свидетельствуют о том, что степень плавления вмещающих пород с образованием гранофировых структур зависит от флюидного режима и температуры вмещающих пород во время внедрения базитовых интрузивов, а роговиковоподобные структуры не являются надежными признаками термального воздействия интрузивов базитов.

Ключевые слова: базиты, термальное воздействие, гранитоиды, гранофировые структуры, роговики.

\section{Varieties of thermal impact of basic rocks intrusions on host rocks and possible reasons of their difference on examples of the north-eastern Basic Shield}

\section{Travin V.V.} Institute of Geology, Karelian Research Center, Russian Academy of Sciences, Petrozavodsk, vetr@list.ru

\begin{abstract}
Granophyric granites (completele melted host rocks), partly (in different degrees) melted rocks with granophiric textures and granitoids with hornfels-like textures are examined in the paper. Different causes of the different thermal influence of basic rocks intrusions are discussed. The data show that the degree of host rocks melting registered in granophiric textures depends on the fluid regime and temperature of host rocks at the time of intrusion, but hornfels-like textures are not direct indicators of thermal influence of basic rocks intrusions.
\end{abstract}

Key words: basic rocks, thermal influence, granitoids, granophyric texture, hornfels.

Интрузивные тела базитов далеко не всегда вызывают плавление вмещающих гранитоидов, несмотря на то, что температура кристаллизации магм основного состава значительно выше температуры плавления гранитов. Более того, очевидные петрографические признаки термального воздействия базитов на вмещающие породы, в качестве которых рассматриваются гранофировые структуры пород и роговики (Полканов, 1955; Елисеев, 1963), не повсеместны.

Эффектными примерами плавления вмещающих пород в результате теплового воздействия интрузивов базитов в пределах рассматриваемой части Балтийского щита являются гранофировые граниты около массива Ципринга и близ восточного окончания оз. Паанаярви. Пространственно они приурочены к крупным телам раннепротерозойского комплекса лерцолитов-габброноритов (КЛГН) с возрастом около 2.5 млрд. лет (Ефимов, Каулина, 1997 и др.) и, по-видимому, генетически связаны с ними, являясь результатом переплавления вмещающих пород. В районе восточного окончания оз. Паанаярви среди слоистых пород карельского $\left(\mathrm{PR}_{1}\right)$ комплекса, метаморфизованных в условиях фации зеленых сланцев, гранофировые граниты слагают массив площадью около 0.5 кв. км (Травин, 1991). Относительно слабая переработка вне массива гранофировых гранитов выражается в локальном образовании гранофировых срастаний кварца и плагиоклаза в слабоизмененной структуре пород (рис. 1 А). Глубокая переработка приводит к образованию лейкократовых гранитов с идиоморфными зернами плагиоклаза и окружающими их гранофировыми каймами, занимающими большую часть объема породы (рис. 1 Б). Различный состав гранофировых гранитов района восточного окончания оз. Паанаярви свидетельствует об их образовании по породам разного состава. К такому же выводу на основе данных изучения гранофировых гранитов в экзоконтак- 


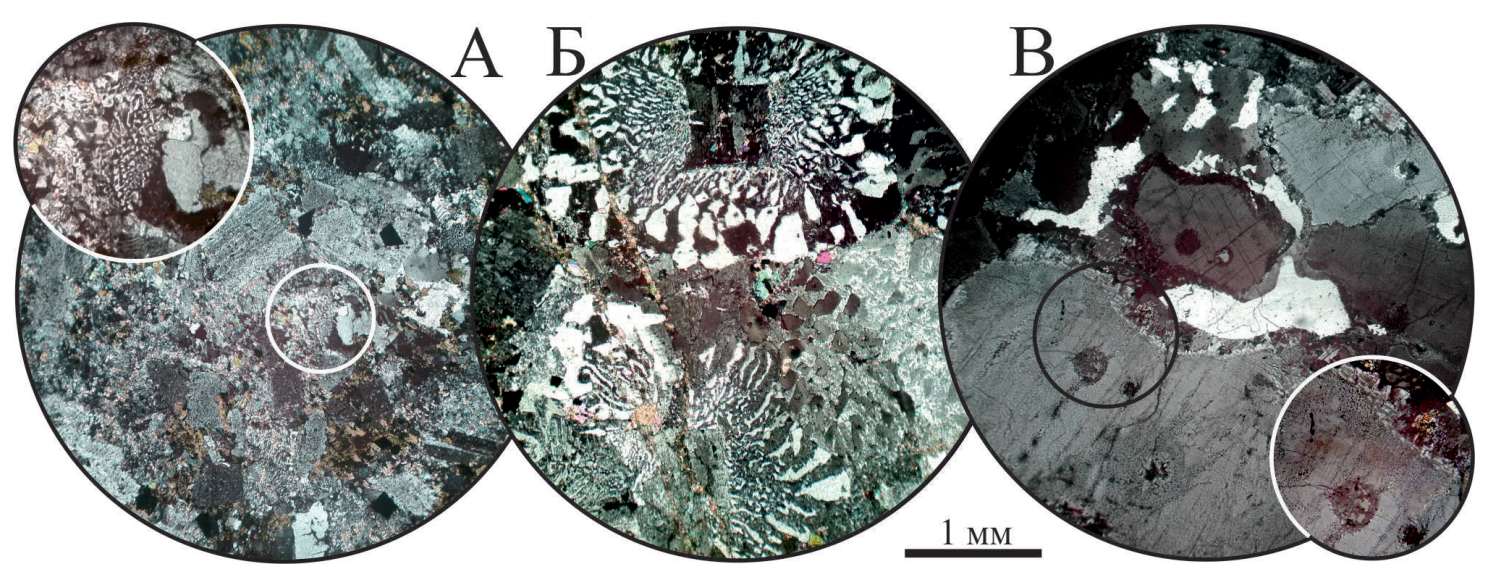

Рис. 1. Гранофировые структуры пород из зон термального воздействия интрузивов базитов. А, Б - Различные степени палингенеза пород близ крупного массива КЛГН, район восточного окончания озера Паанаярви. А - андезитовый порфирит с локально проявленным гранофиром - продуктом его частичного плавления. Б - палингенный гранофировый гранит - результат переплавления первичной породы (кварцевого порфира (?)). В - реакционные гранофировые каймы на границах и внутри (врезка) зерен плагиоклаза в гнейсограните из экзоконтакта дайки района порта Гремиха.

Fig. 1. Granophyric textures of rocks from zones of basic intrusion thermal influence. A, Б-Different degrees of rocks palingenesis near large gabbronorite intrusion, Paanajarvi lake area. A - Andesitic porphyrite with local (in situ) granophyre - result of partial melting of rock. $\mathrm{B}$ - Granophyric granite - result of complete melting of quartz porphyry (?). B - Granophyric border rims of plagioclase and quartz grains in gneiss near the dyke contact.

товых зонах массивов Ципринга и Кивакка КЛГН пришли ранее В.В. Сидоренко, В.В. Фиженко и К.А. Шуркин (Геология и магматизм.., 1974).

Примером экзоконтактовых пород базитовых интрузивов с отсутствием явных петрографических признаков термального воздействия базитов служат гнейсограниты в экзоконтакте крупной дайки габбро между портом Гремиха и городом Островной. Фанерозойская (?) дайка сложена диабазами с магматической структурой, имеет мощность более 15 м, двухметровую зону закалки, породы которой в эндоконтакте представлены вулканическим стеклом с включениями мелких зерен плагиоклаза и клинопироксена. Гнейсограниты в экзоконтакте - обычные для района среднезернистые породы со слабо проявленной гнейсовидностью.

Отсутствие признаков термального воздействия интрузивов базитов на «легкоплавкие» гранитоиды легко объяснимо в случаях, когда породы испытали совместные наложенные, оторванные во времени от акта внедрения, интенсивные синметаморфические деформации с образованием новых метаморфических текстур гранитоидов, облекающих тела базитов. Такая ситуация обычна для восточной части Балтийского щита, испытавшей синдеформационный метаморфизм на заключительной, свекофеннской (1.9-1.8 млрд. лет назад), стадии своего структурно-метаморфического формирования.

Но при наложении низкотемпературного метаморфизма, не вызывающего полной перекристаллизации пород, в гранитоидах экзоконтактов базитовых интрузивов гранофировые структуры могут сохраняться. На рис. 1 В представлены гранофировые срастания на контактах зерен минералов в гнейсограните экзоконтакта недеформированной раннедокембрийской дайки района порта Гремиха. Связь гранофировых структур в гнейсограните с дайками базитов в подобных случаях представляется очевидной.

При отсутствии интенсивных деформаций, признаки термальной переработки вмещающих гранитоидов могут также сохраняться и в условиях высокотемпературного наложенного метаморфизма. Это касается и Беломорского подвижного пояса, породы которого испытали свекофеннский метаморфизм в условиях амфиболитовой фации. Среди примеров - породы контактовой зоны интрузива Юдомнаволок-Кузема, где гранофировые срастания кварца и полевых шпатов отмечены как в габброноритах эндоконтакта, так и во вмещающих гранитоидах, испытавших термальное воздей- 

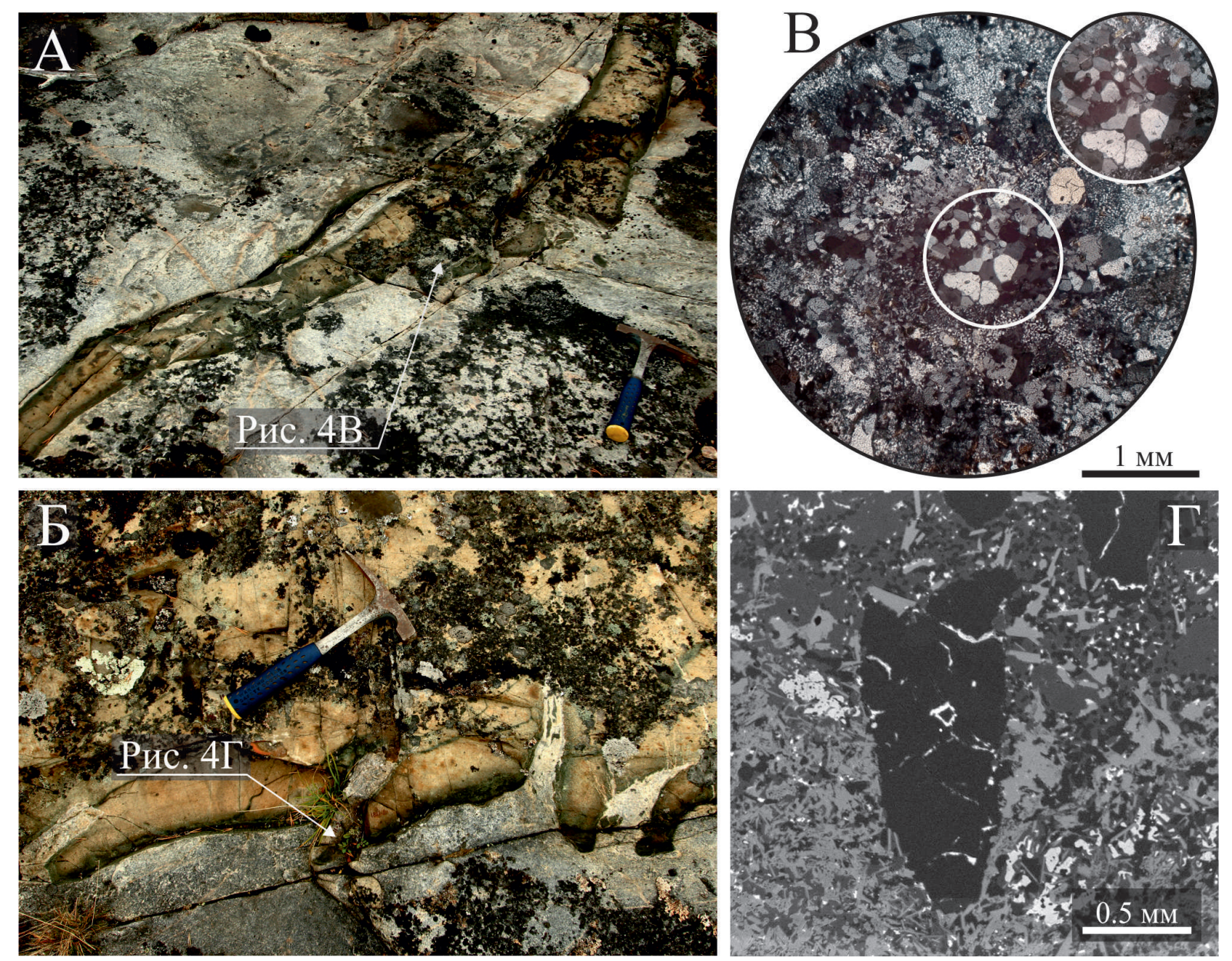

Рис. 2. Структурные особенности гранитов в экзоконтактах апофиз дайки габбронорита КЛГН, район села Гридино. А, Б - массивные граниты на контактах с мелкой (А) и крупной, мощностью 4 м, апофизы (Б). В-Г - структуры пород. В - структура гранита. Мономинеральные агрегаты зерен плагиоклаза в тонкозернистом гранофире - псевдоморфозы по более крупным зернам плагиоклаза. Г- мономинеральный агрегат зерен кварца на границе сильно измененного габбронорита (внизу) и гранита (вверху).

Fig. 2. Structural peculiarities of granites in exocontacts of gabbronorite dyke apophyses, Gridino village area. А, Б - Massive granites around small apophysis (A); contact of granites with thick (4 m width) apophyses (Б). $\mathrm{B}, \Gamma-$ Textures of rocks. B - Texture of granite. Monomineral plagioclase aggregates in fine-grained granophyres - pseudomorphs of primary bigger grains of plagioclase (?). $\Gamma$ - Monomineral quartz aggregate at the border of metamorphosed gabbronorite (at the bottom) and granite (at the top).

ствие массива (Степанов, 1981). Схожие контактовые преобразования гранитоидов, сохранившиеся при наложенном метаморфизме амфиболитовой фации, выявлены на контактах некоторых деформированных даек габброноритов КЛГН в районе села Гридино, Карельский берег Белого моря (рис. 2). Макроскопически преобразования вмещающих пород выражены в перекристаллизации пород с утратой гнейсовидности: гнейсограниты преобразованы в основном в граниты гранат-биотиткварц-полевошпатового состава с массивной текстурой (рис. 2 А, Б). Структуры пород разнозернистые (рис. 2 В). В тонкозернистом гранофире неравномерно распределены мелкозернистые кварцевые и плагиоклазовые агрегаты, вероятно, представляющие собой псевдоморфозы по более крупным зернам плагиоклаза и окружены тонкозернистыми гранофировыми каймами (рис. 2 В). В гранитах присутствуют вытянутые, в том числе и субпараллельные, и изометричные мономинеральные агрегаты кварца. Местами агрегаты кварца пересекают контакты гранита и метагаббронорита (рис. 2 Г). Пластины биотита в гранитах не имеют предпочтительной ориентировки. Такие особенности структур гранитов, не проявленные на удалении от даек, свидетельствуют об их образовании в результате теплового воздействия даек. 
Гранитоиды с простыми полигональными формами зерен (с гранобластовыми структурами, подобными структурам роговиков) встречаются в экзоконтактах даек довольно часто. Такую структуру имеют, например, гнейсограниты в экзоконтакте крупной (около 30 м мощности) дайки габбронорита КЛГН района села Гридино (рис. 3 А), но структура гнейса ксенолита ( $1 \times 2$ м) во внутренней части этой дайки иная (рис. 3 Б). Гнейсы на значительном удалении от этой дайки (рис. 3 В) по структуре схожи с породами экзоконтакта, что делает сомнительной обусловленность роговиковоподобной структуры гранитоида в экзоконтакте дайки тепловым воздействием базитового магматического расплава. Поэтому гранобластовые структуры представляются ненадежными индикаторами теплового воздействия интрудирующих тел базитов.

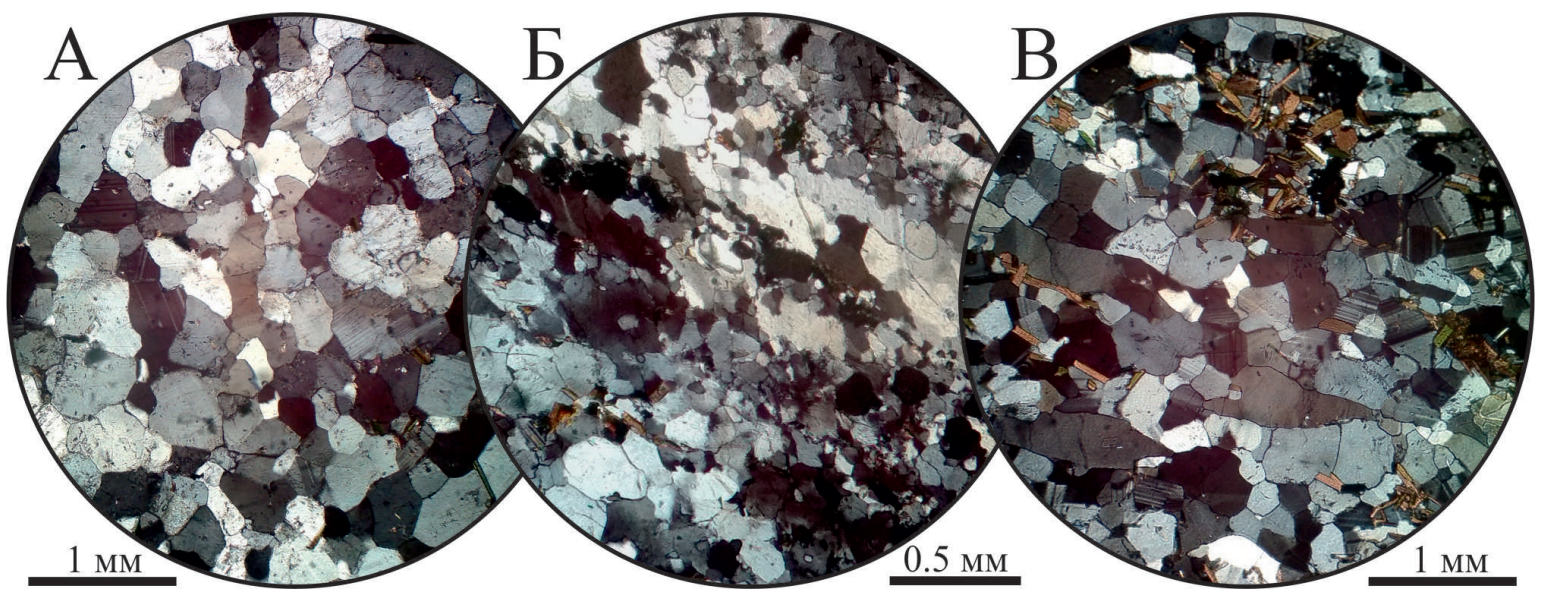

Рис. 3. Структуры гранитоидов в зоне и вне зоны воздействия дайки. А - роговиковоподобная структура биотитового гнейсогранита в экзоконтакте крупной дайки габбронорита КЛГН района села Гридино. Б - структура гранат-биотитового гнейсогранита в ксенолите из внутренней части дайки. В - структура биотитового гнейсогранита на удалении 0.1 км от этой дайки.

Fig. 3. Granitoid textures near and far from the gabbronorite dyke. A - Hornfels-like texture of biotite gneiss garnet in the exocontact of gabbronorite in the Gridino area. $\mathrm{B}$ - The texture of garnet-biotite gneiss granite in xenolith from inner part of the dyke. B - Texture of biotite gneiss garnet over a distance of about $0.1 \mathrm{~km}$ from the contact of the dyke.

Причины различий термального воздействия базитовых интрузивов не очевидны. В случаях отсутствия явных петрографических признаков термального воздействия «по умолчанию» это связывается с «сухими» условиями при внедрении интрузивов, либо с теплоизолирующими свойствами зон закалки интрузивов.

Флюид рассматривается как непременный участник процессов плавления гранитоидов (Полканов, 1955), при увеличении количества которого температура плавления гранитоидов снижается (Саранчина, Шинкарев, 1967). При том, что базитовый расплав рассматривается как источник флюидов (Полканов, 1955 и др.), с «флюидных позиций» не ясно, почему неповсеместны процессы палингенеза гранитоидов в эндоконтактах крупных даек.

Теплоизолирующий эффект зон закалки даек объясняется, например, моделью формирования силла с оболочкой (зоной закалки) при повторяющемся поступлении расплава в его центр, объясняющей малый ореол термического воздействия интрузива (30-60 \% его толщины) и температуру в зоне контакта интрузивного массива с вмещающими породами на $200-500{ }^{\circ} \mathrm{C}$ ниже температуры магматического расплава (Галушкин, 1999). Эти теоретические построения объясняют «отсутствие признаков эффективного преобразования пород в контактовых зонах многих даек и силлов» и некорректность «модели мгновенной «интрузии», согласно которой «интрузия может вызывать существенное влияние на созревание пород, удаленных на расстояние 1-1.5 толщин интрузии» (там же, с. 1197).

Кроме того, теплоемкость минералов базитов меньше теплоемкости минералов гранитоидов (Петрушин, Попов, 2011), что определяет относительно невысокий тепловой ресурс остывающих 
базитов. Однако, в случае, когда крупная дайка базитов в центральной своей части содержит небольшой ксенолит гранитоидов, объяснение отсутствия в нем очевидных признаков термического воздействия базитового расплава (рис. 3 Б) с позиций теплоизолирующего эффекта пород эндоконтакта либо малой теплоемкости базитов представляется проблематичным.

Изучение в различной степени деформированных даек Западного Прибайкалья, сложенных базитами с хорошей сохранностью магматических структур и окруженных «рубашками» пегматоидных гранитов привело исследователей Ольхонской коллизионной системы к выводу о синметаморфическом внедрении даек базитов (Скляров и др., 2001). По их мнению, выплавление значительного количества гранитов, образующих «рубашки» даек «маломощными субвертикальными инъекциями долеритов $\left(T=1100-1300^{\circ} \mathrm{C}\right)$ возможно только в случае, если температура среды близка к субэвтектической для гранитного расплава» (там же, с. 525).

Для случая, иллюстрированного рисунком 2, по-видимому, именно высокая температура вмещающих гранитоидов стала причиной их преобразований при тепловом воздействии внедрявшейся дайки. В пользу синметаморфического внедрения дайки свидетельствуют и структурные особенности апофиз (рис. 2 А, Б), необъяснимые наложенными, оторванными во времени от этапа внедрения дайки, деформациями. Но такое объяснение не является универсальным: наиболее эффектный пример палингенного преобразования пород, иллюстрированный рисунком 1 Б, представлен гранитами, слагающими массив среди пород, метаморфизованных в условиях низкотемпературной фации зеленых сланцев, и удаленный от интрузива базитов на расстояние около 1 км.

Глубина термальной переработки определяется, по-видимому, действием разных факторов, роль каждого из которых может быть различной. Рассматриваемые примеры представляется логичным объяснить следующим образом. Выплавки палингенных гранитов среди слоистых пород карельского комплекса, метаморфизованных в условиях фации зеленых сланцев, вероятно, связаны с метаморфизмом и высокой флюидонасыщенностью карельских пород во время внедрения и остывания интрузива базитов. Характер и масштабы контактово-термальных преобразований гранитоидов определяются их температурой (прогревом), отражающей глубину внедрения массивов базитов. В любом случае, термальные преобразования вмещающих пород, вызванные интрузиями базитов, являются индикаторами геодинамических обстановок.

Работа выполнена в рамках базовой темы НИР № АААА-А18-118020290084-7 Института геологии КарНЦ РАН при частичной поддержке РФФИ (грант № 17-05-00329).

\section{Литература}

1. Галушкин Ю.И. Термический ореол интрузии и возможный механизм ее вмещения в осадочный разрез поднятия Кэйп-Верде // Геохимия. 1999. №11. С. 1197-1205.

2. Ефимов А.А., Каулина Т.В. Геологические особенности и U-Pb датирование (первые данные) юговосточной части Ковдозерского базит-гипербазитового массива (блок Пуахта) // Беломорский подвижный пояс (геология, геодинамика, геохронология): тез. докл. Петрозаводск: Кар НЦ РАН. 1997. С. 31.

3. Елисеев Н.А. Метаморфизм. М.: Недра. 1963. 428 c.

4. Петрушин Г.И., Попов В.Г. Теплофизические свойства вещества Земли. Учебное пособие. Ч. 1. М. Издво: Физический факультет МГУ. 2011. 68 с.

5. Полканов А.А. Проблема происхождения гранитов платформенных областей и геология, магматизм и граниты эпохи хогландия-иотния южной части Балтийского щита // Труды лаборатории геологии докембрия. Вып. 5. М.-Л. Изд-во: АН СССР. 1955. С. 5-43.

6. Саранчина Г.М., Шинкарев Н.Ф. Петрография магматических и метаморфических пород. Л. Изд-во: Недра. $1967.324 \mathrm{c}$.

7. Скляров Е.В., Федоровский В.С., Гладкочуб Д.П., Владимиров А.Г. Синметаморфические базитовые дайки - индикаторы коллапса коллизионной структуры Западного Прибайкалья // Докл. Академии наук. 2001. T. 381. № 4. C. 522-527.

8. Травин В.В. Раннекарельские граниты Паанаярвинской структуры // Геология и рудогенез докембрия Карелии. Опер.-информ.материалы за 1990 г. Петрозаводск: Карельский НЦ АН СССР. 1991. С. 8-10.

9. Шуркин К.А., Шемякин В.М., Пушкарев Ю.Д., Сидоренко В.В., Фиженко В.В., Берковский А.Н., Шустова Л.Е. Геология и магматизм области сочленения беломорид и карелид (Беломорско-Карельский глубинный разлом). Л. Изд-во: Наука. 1974. 184 с. 